\title{
Detection and Characterization of Human Pegivirus 2, Vietnam
}

\section{Nguyen To Anh, Nguyen Thi Thu Hong, Le Nguyen Truc Nhu, Tran Tan Thanh, Catherine Anscombe, Le Ngoc Chau, Tran Thi Thanh Thanh, Chuen-Yen Lau, Direk Limmathurotsakul, Nguyen Van \\ Vinh Chau, H. Rogier van Doorn, Xutao Deng, Motiur Rahman, Eric Delwart, Thuy Le, Guy Thwaites, Le Van Tan, for the Southeast Asia Infectious Disease Clinical Research Network ${ }^{1}$}

We report human pegivirus 2 (HPgV-2) infection in Vietnam. We detected HPgV-2 in some patients with hepatitis $C$ virus/ HIV co-infection but not in patients with HIV or hepatitis A, B, or $C$ virus infection, nor in healthy controls. HPgV-2 strains in Vietnam are phylogenetically related to global strains.

$\mathrm{H}$ uman pegivirus 2 ( $\mathrm{HPgV}-2)$, also known as human hepegivirus 1 , is a recently discovered bloodborne flavivirus $(1,2)$. Existing evidence suggests that HPgV2 is more frequently detected in patients with hepatitis $\mathrm{C}$ virus (HCV) infection, particularly $\mathrm{HCV}$ and $\mathrm{HIV}$ co-infection, although detection rates vary between studies and patient groups. In the United States, HPgV-2 was detected in $1.2 \%(12 / 983)$ of patients with active HCV infections (1), whereas in China, the reported detection rates of HPgV-2 RNA were $0.29 \%$ (7/2440) among HCV monoinfected patients and from $3 \%(8 / 270)$ to $5.7 \%(4 / 70)$ among HCV/HIV co-infected patients $(3,4)$. HPgV-2 RNA was detected in $10.9 \%(17 / 156)$ of injection drug users in the United States, and there was a strong association between $\mathrm{HPgV}-2$ and other infections such as HCV and SEN virus $\mathrm{D}(5)$.

Author affiliations: Oxford University, Ho Chi Minh City, Vietnam (N.T. Anh, N.T.T. Hong, L.N.T. Nhu, T.T. Thanh, C. Anscombe, L.N. Chau, T.T.T. Thanh, H.R. van Doorn, M. Rahman, T. Le, G. Thwaites, L.V. Tan); University of Oxford, Oxford, UK (C. Anscombe, D. Limmathurotsakul, H.R. van Doorn, G. Thwaites); National Institutes of Health, Bethesda, Maryland, USA (C.-Y. Lau); Mahidol Oxford Tropical Research Unit, Bangkok, Thailand (D. Limmathurotsakul); Hospital for Tropical Diseases, Ho Chi Minh City, Vietnam (N.V.V. Chau); Blood Systems Research Institute, San Francisco, California, USA (X. Deng, E. Delwart); University of California, San Francisco (X. Deng, E. Delwart)

DOI: https://doi.org/10.3201/eid2411.180668
Given the high burden of HCV and HIV infections worldwide and the potential clinical significance of $\mathrm{HPgV}$ 2 , we investigated the geographic distribution and genetic diversity of this virus to help prioritize the development and implementation of appropriate intervention strategies. The studies were approved by the corresponding institutional review boards of the local hospitals in Vietnam where patients were enrolled and the Oxford Tropical Research Ethics Committee. We obtained written informed consent from each participant or from the participant's parent or legal guardian.

\section{The Study}

Patient information and clinical samples were derived from a multilocation observational study designed to evaluate the causes of community-acquired infection in Southeast Asia (6). We included all 493 samples (384 plasma, 92 pooled nasal and throat swabs, 10 stool, and 7 cerebrospinal fluid [CSF]) from 386 patients in Vietnam with community-acquired infection of unknown origin after extensive diagnostic workup for viral metagenomic analysis (7).

Analysis of metagenomic data revealed that, in 1 plasma sample, of 98,344 obtained reads, 5,342 reads were of $\mathrm{HCV}$ sequences, 430 of HIV sequences, and 273 of $\mathrm{HPgV}$ 2 sequences; we confirmed all reads by corresponding virus-specific reverse transcription PCR (RT-PCR). HPgV-2 sequence screening and $\mathrm{HPgV}-2 \mathrm{RT}-\mathrm{PCR}$ testing did not detect $\mathrm{HPgV}-2$ in any of the remaining samples of the patients included in metagenomic analysis.

To explore the prevalence of $\mathrm{HPgV}-2$ in $\mathrm{HCV}$-infected patients in Vietnam, we used a reference-based mapping strategy to screen for $\mathrm{HPgV}-2$ sequences in additional viral metagenomic datasets (Table 1). We detected HPgV-2 sequences in 5/79 HIV/HCV co-infected patients who participated in a trial evaluating the hepatic safety of raltegravir/efavirenz-based therapies in antiretroviral-naive HIVinfected subjects co-infected with HCV. We did not detect $\mathrm{HPgV}-2$ sequences in $394 \mathrm{HCV}$-infected patients with clinically diagnosed hepatitis who participated in molecular epidemiologic studies of hepatitis viruses (Table 1).

We subsequently confirmed the result of this reference-mapping approach by HPgV-2 multiplex RT-PCR (8) testing of the extracted RNA from original samples. We

${ }^{1}$ Members of the Southeast Asia Infectious Disease Clinical Research Network are listed at the end of this article. 
Table 1. Samples and viral metagenomic datasets used in screening for HPgV-2 and screening results, Vietnam*

\begin{tabular}{|c|c|c|c|c|c|}
\hline Infection & $\begin{array}{c}\text { No. } \\
\text { persons }\end{array}$ & Screening approach & $\begin{array}{l}\text { No. positive } \\
\text { for HPgV-2 }\end{array}$ & $\begin{array}{l}\text { Enrollment } \\
\text { period }\end{array}$ & Setting \\
\hline $\begin{array}{l}\text { Hepatitis } \mathrm{C} \text { virus } \\
\text { and HIV co- } \\
\text { infection }\end{array}$ & 79 & $\begin{array}{l}\text { HPgV-2-specific PCR } \\
\text { and reference-based } \\
\text { mapping of obtained } \\
\text { viral metagenomics data }\end{array}$ & 5 & $2010-2013$ & $\begin{array}{c}\text { Hospital for Tropical Diseases, } \\
\text { Ho Chi Minh City }\end{array}$ \\
\hline HIV monoinfection & 78 & HPgV-2-specific PCR & 0 & 2010-2013 & $\begin{array}{c}\text { Hospital for Tropical Diseases, } \\
\text { Ho Chi Minh City }\end{array}$ \\
\hline $\begin{array}{l}\text { None (healthy } \\
\text { volunteers) }\end{array}$ & 80 & HPgV-2-specific PCR & 0 & $2010-2013$ & $\begin{array}{c}\text { Hospital for Tropical Diseases, } \\
\text { Ho Chi Minh City }\end{array}$ \\
\hline Hepatitis A virus & 71 & HPgV-2-specific PCR & 0 & 2012-2014 & $\begin{array}{l}\text { Hospital for Tropical Diseases, } \\
\text { Ho Chi Minh City }\end{array}$ \\
\hline Hepatitis B virus & 103 & HPgV-2-specific PCR & 0 & 2012-2016 & $\begin{array}{c}\text { Hospital for Tropical Diseases, } \\
\text { Ho Chi Minh City; Dong Thap General } \\
\text { Hospital, Dong Thap; Khanh Hoa Provincial } \\
\text { Hospital, Nha Trang; Dac Lac Provincial } \\
\text { Hospital, Dac Lac; Hue National Hospital, Hue }\end{array}$ \\
\hline Hepatitis $\mathrm{C}$ virus $\dagger$ & 394 & $\begin{array}{c}\text { Reference-based } \\
\text { mapping of obtained } \\
\text { viral metagenomics data }\end{array}$ & 0 & $2012-2016$ & $\begin{array}{c}\text { Hospital for Tropical Diseases, } \\
\text { Ho Chi Minh City; Dong Thap General } \\
\text { Hospital, Dong Thap; Khanh Hoa Provincial } \\
\text { Hospital, Nha Trang; Dac Lac Provincial } \\
\text { Hospital, Dac Lac; Hue National Hospital, Hue }\end{array}$ \\
\hline
\end{tabular}

${ }^{*} \mathrm{HPgV}-2$, human pegivirus.

†Whole-genome sequences of hepatitis $C$ virus were obtained using a viral metagenomics approach (7). The resulting metagenomics datasets were then subjected to a reference-based mapping approach to search for the presence of HPgV-2 sequences.

conducted multiplex RT-PCR screening for HPgV-2 RNA in plasma samples of matched controls (78 HIV-infected patients and 80 healthy volunteers) of the $79 \mathrm{HCV} / \mathrm{HIV}$ coinfected patients; we found no evidence of $\mathrm{HPgV}-2$ (Table 1). In addition, we did not detect HPgV-2 RNA in any plasma samples from patients with HAV $(\mathrm{n}=71)$ and HBV $(\mathrm{n}$ $=103$ ) infection (Table 1).

$\mathrm{HPgV}-2$ RNA was detectable for $\leq 18$ months in $3 / 5$ patients with HCV/HIV co-infection (Table 2). We did not detect HPgV-2 RNA in the available follow-up serum sample collected 14 days after enrollment from the patient with community-acquired infection (Table 2).

All $5 \mathrm{HCV} / \mathrm{HIV}$ co-infected patients had CD4 counts $>200$ cells $/ \mu \mathrm{L}$ at baseline and at 6-, 12-, and 18-month follow-up (Table 2), but none received specific anti-HCV drugs, which was attributed to drug unavailability or unaffordability during the study period. During follow-up, hepatitis and splenic abnormalities were detected in 4/5 patients, which were likely attributable to HCV infection (Table 2). The patient with community-acquired infection was recorded as surviving to 28 days of follow-up (Table 2).

Using deep sequencing and a combination of overlapping PCRs and Sanger sequencing of PCR amplicons (primer sequences available upon request), we obtained 5 nearly complete genomes (coverage of $>92 \%$ ) and another partial genome (coverage of $\approx 69.1 \%$ ). Pairwise comparison of $\mathrm{HPgV}-2$ coding regions obtained in this study and previously reported $\mathrm{HPgV}-2$ sequences showed overall sequence identities at the nucleotide level of $\geq 94.6 \%$ and at the amino acid level of $\geq 95.3 \%$ (data not shown).
Phylogenetic analyses revealed a tight cluster between viruses from Vietnam and global strains (Figure). We submitted the HPgV-2 sequences we generated to GenBank (accession nos. MH194408-13).

Of the $5 \mathrm{HPgV}-2$ genome sequences we recovered, we generated 2 by deep sequencing. The results were above the proposed sequencing-depth threshold of $\geq 5$ for sequences generated by next-generation sequencing ( 9 ) and sufficient for intrahost diversity investigation. One sequence we generated had mean coverage of 2,049 (range 12-9,912), with a total of $26(10[38 \%]$ nonsynonymous) positions carrying minor variations detected in the corresponding dataset (data not shown). For the other sequence, mean coverage was 32,531 (range 13-138,383), with a total of 37 (13 [35\%] nonsynonymous) positions carrying minor variations in its dataset (data not shown).

\section{Conclusions}

We report the detection and genetic characterization of HPgV-2 in Vietnam and describe the observed demographic and clinical characteristics of patients with HPgV-2 infection. Together with reports from China, Iran, and the United States $(1-4,8,10)$, our findings further emphasize the strong association between $\mathrm{HPgV}-2$ and $\mathrm{HCV}$, especially HCV/HIV co-infection. The absence of HPgV-2 in $394 \mathrm{HCV}$-infected patients may have been attributed to the small sample size and the fact that the reported prevalence of HIV among HCV-infected patients was $\leq 6.5 \%(11,12)$. Of note, HPgV-2 was detected in only $0.29 \%$ of HCVmonoinfected patients in China. 
Table 2. Demographic and clinical features of 6 men with human pegivirus infection, Vietnam*

\begin{tabular}{|c|c|c|c|c|c|c|c|c|c|c|c|c|c|}
\hline $\begin{array}{l}\mathrm{Pt} \\
\text { no. }\end{array}$ & $\begin{array}{c}\mathrm{Pt} \\
\mathrm{age},\end{array}$ & $\begin{array}{c}\text { Time } \\
\text { point, } \\
\text { mo }\end{array}$ & $\begin{array}{l}\text { HCV } \\
\text { RNA+ }\end{array}$ & $\begin{array}{l}\text { HPgV-2 } \\
\text { RNA+ }\end{array}$ & $\begin{array}{c}\text { Total } \\
\text { bilirubin, } \\
\mu \mathrm{mol} / \mathrm{L}\end{array}$ & $\begin{array}{c}\text { Direct } \\
\text { bilirubin, } \\
\mu \mathrm{mol} / \mathrm{L}\end{array}$ & $\begin{array}{l}\text { AST, } \\
\text { UI/L }\end{array}$ & $\begin{array}{l}\mathrm{ALT} \\
\mathrm{UI} / \mathrm{L}\end{array}$ & $\begin{array}{c}\text { CD4 } \\
\text { count, } \\
\text { cells/ } \mu \mathrm{L}\end{array}$ & $\begin{array}{l}\text { HIV RNA, } \\
\times 10^{3} \\
\text { copies/ } / \mu \mathrm{L}\end{array}$ & $\begin{array}{l}\text { AFP, } \\
\mathrm{mg} / \mathrm{mL}\end{array}$ & $\begin{array}{l}\text { FibroScan } \\
\text { result, } \mathrm{kPa}\end{array}$ & Symptoms \\
\hline 1 & 29 & NA & $\mathrm{NA}$ & NA & NA & NA & NA & $\mathrm{NA}$ & NA & NA & NA & NA & NA \\
\hline \multirow[t]{4}{*}{2} & 47 & 0 & $\bar{Y}$ & $\bar{Y}$ & 9.8 & 0.7 & 30 & 24 & 331 & 120 & 1.7 & 11.8 & \\
\hline & & 6 & Y & Y & 4.7 & 1.6 & 81 & 83 & 518 & 0.07 & 2.3 & NA & \\
\hline & & 12 & Y & $Y$ & 6.9 & 3.4 & 55 & 61 & 364 & 0.04 & 2.6 & 11.8 & Hepatitis \\
\hline & & 18 & Y & $Y$ & 4.8 & 2.8 & 37 & 40 & 428 & UND & 2.14 & 6.1 & Hepatomegaly \\
\hline \multirow[t]{4}{*}{3} & 32 & 0 & $\mathrm{Y}$ & $\mathrm{Y}$ & 4.7 & 3.4 & 39 & 10 & 288 & 0.198 & 0.999 & 6.5 & \\
\hline & & 6 & Y & $Y$ & 12.8 & 4.7 & 50 & 19 & 510 & 0.04 & 1.68 & NA & \\
\hline & & 12 & Y & Y & 9.5 & 5.3 & 63 & 25 & 622 & UND & 1.88 & 6.2 & $\begin{array}{l}\text { Liver fibrosis, } \\
\text { hepatomegaly }\end{array}$ \\
\hline & & 18 & $Y$ & Y & 7.6 & 3.8 & 42 & 23 & 622 & UND & 1.53 & 7.2 & Hepatitis \\
\hline \multirow[t]{4}{*}{4} & 35 & 0 & $\bar{Y}$ & $\bar{Y}$ & 7.8 & 4.9 & 67 & 55 & 290 & 61.1 & 2.96 & 6.4 & \\
\hline & & 6 & Y & $Y$ & 10.7 & 6.3 & 77 & 80 & 411 & UND & 3.1 & NA & \\
\hline & & 12 & $Y$ & $Y$ & 8.8 & 3.9 & 76 & 72 & 337 & UND & 4 & 8.5 & $\begin{array}{l}\text { Homogeneous } \\
\text { hepatomegaly }\end{array}$ \\
\hline & & 18 & $Y$ & $Y$ & 13 & 6.3 & 108 & 129 & 455 & UND & 4.1 & 8.1 & $\begin{array}{l}\text { Splenomegaly, } \\
\text { liver fibrosis }\end{array}$ \\
\hline \multirow[t]{4}{*}{5} & 34 & 0 & $\mathrm{Y}$ & $Y$ & 4.3 & 2.8 & 33 & 43 & 291 & 70.2 & 3.67 & 6.1 & \\
\hline & & 6 & $\mathrm{~N}$ & $Y$ & 6.5 & 2.1 & 35 & 43 & 287 & UND & 3.83 & NA & \\
\hline & & 12 & $\mathrm{~N}$ & $N$ & 5.4 & 2.6 & 33 & 40 & 484 & UND & 4.48 & 4.5 & \\
\hline & & 18 & $\mathrm{~N}$ & $\mathrm{~N}$ & 6.6 & 2.6 & 73 & 85 & 546 & UND & 3.9 & 3 & \\
\hline \multirow[t]{4}{*}{6} & 31 & 0 & $\mathrm{Y}$ & $\bar{Y}$ & 4.5 & 2.4 & 52.2 & 36.5 & 295 & 96.8 & 12.7 & 22.8 & \\
\hline & & 6 & $Y$ & $Y$ & 17.1 & 12.9 & 64 & 62 & 579 & UND & 16.74 & NA & \\
\hline & & 12 & $Y$ & $\mathrm{~N}$ & 12.3 & 4.3 & 114 & 121 & 711 & UND & 46.3 & 26.3 & $\begin{array}{c}\text { Mild liver } \\
\text { fibrosis, mild } \\
\text { splenomegaly }\end{array}$ \\
\hline & & 18 & $Y$ & $\mathrm{~N}$ & 10.6 & 4.9 & 82 & 89 & 816 & UND & 61.01 & NA & $\begin{array}{l}\text { Hepatomegaly, } \\
\text { splenomegaly }\end{array}$ \\
\hline
\end{tabular}

Previous reports showed that $\mathrm{HPgV}-2$ viremia can be transient or persistent. Likewise, in our study, HPgV-2 RNA became undetectable after 14 days in a HCV/HIV coinfected patient with community-acquired infection of unknown origin, but remained detectable in other HCV/HIV co-infected patients through up to 18 months of follow-up.

The pathogenic potential of $\mathrm{HPgV}-2$ remains unknown. Its role in $\mathrm{HCV} / \mathrm{HIV}$ co-infection and response to treatment warrants further research, given its low detection rates in blood donors in the United States and China $(1,3)$ and its absence in healthy persons (this study) but close association with $\mathrm{HCV} / \mathrm{HIV}$ co-infection.

In the era of sequence-based virus discovery, a key question is whether the detected genome represents live virus or a non-replication competent genome. Addressing this question would require recovery of virus in cell culture. However, our detection of minor variations across $2 \mathrm{HPgV}-2$ genomes suggests that viral replication had occurred in the infected patients. Phylogenetically, the close relatedness between $\mathrm{HPgV}-2$ strains from Vietnam and global strains suggests $\mathrm{HPgV}-2$ has a wide geographic distribution.

Our study has some limitations. First, we only retrospectively tested available archived samples without formal sample size estimation, which may have explained the absence of HPgV-2 in the remaining $394 \mathrm{HCV}$ patients. Second, we did not employ a serologic assay to screen for HPgV-2 antibodies in patients' plasma. Third, we used only multiplex PCR with primers based on a limited number of available $\mathrm{HPgV}-2$ sequences. Therefore, we may have missed genetically diverse $\mathrm{HPgV}-2$ strains, and we may have underestimated the prevalence of $\mathrm{HPgV}-2$ infections in Vietnam.

Our findings contribute expanded data about geographic distribution, demographics, and genetic diversity of $\mathrm{HPgV}-2$. Because HCV and HIV infections are global public health issues, the extent to which HPgV-2 interacts with HCV and HIV in co-infected patients and the possible clinical consequences warrant further research.

Members of the Southeast Asia Infectious Disease Clinical Research Network: Pratiwi Sudarmono (Cipto Mangunkusumo Hospital, Jakarta, Indonesia); Abu Tholib Aman (Sardjito Hospital, Yogyakarta, Indonesia); Mansyur Arif (Wahidin Soedirohusodo Hospital, Makassar, Indonesia); Armaji Kamaludi Syarif, Herman Kosasih, and Muhammad Karyana (National Institute of Health Research and Development, Jakarta); Tawee Chotpitayasunondh and Warunee Punpanich Vandepitte (Queen Sirikit National Institute of Child Health, Bangkok, Thailand); Adiratha Boonyasiri, Keswadee Lapphra, Kulkanya Chokephaibulkit, Pinyo Rattanaumpawan, and Visanu Thamlikitkul (Siriraj Hospital, Bangkok, Thailand); Direk Limmathurotsakul, Janjira Thaipadungpanit, Stuart Blacksell, and Nicholas Day (Mahidol-Oxford Tropical 


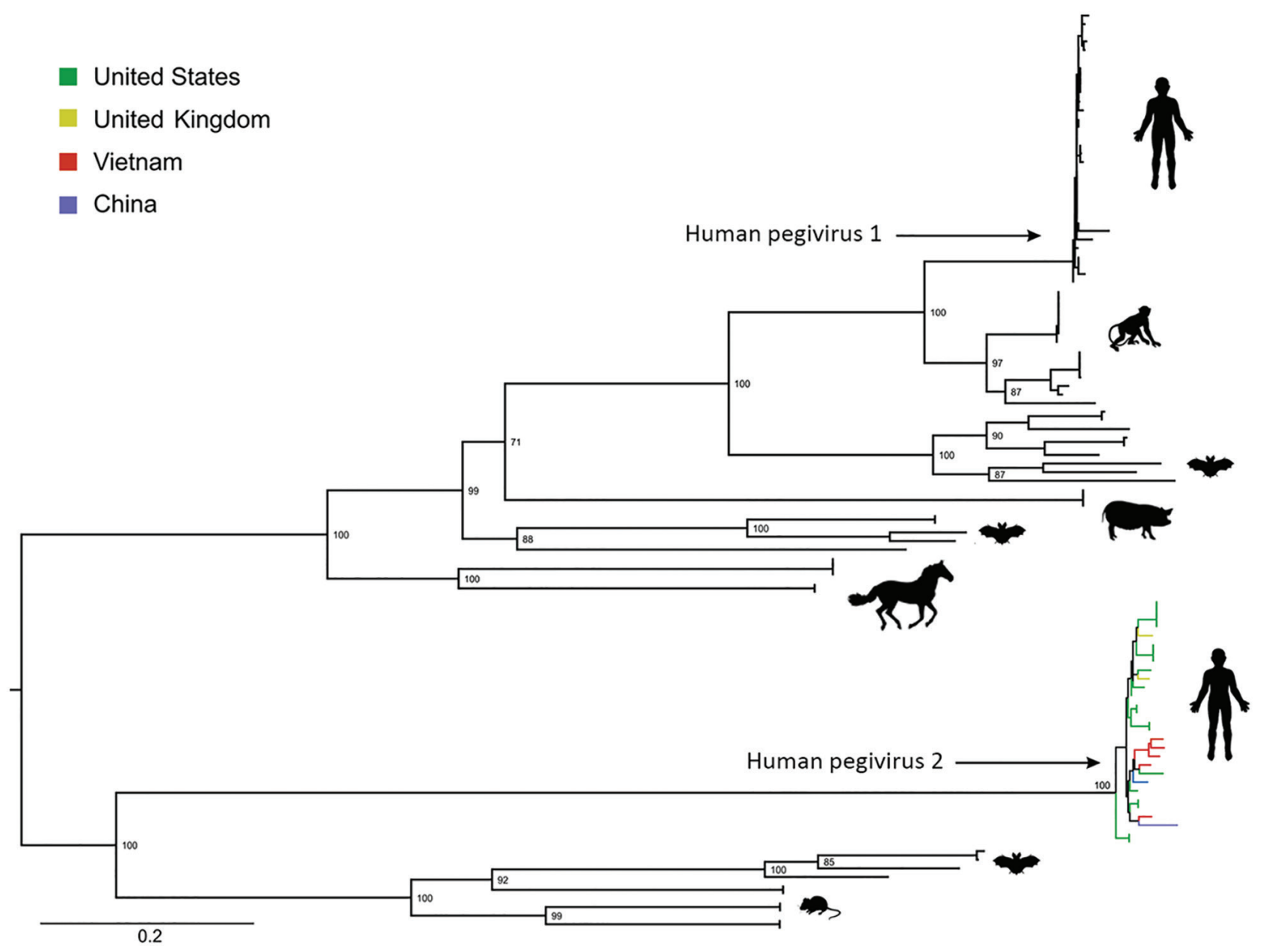

Figure. Maximum-likelihood phylogenetic tree of amino acid sequences of coding sequences of human pegivirus 2 strains from Vietnam compared with global strains and other pegiviruses. We used the general matrix with empirical amino acid frequencies, a gamma distribution of 4 rates, and invariant sites, as suggested by IQ TREE (http://www.iqtree.org), to reconstruct the phylogenetic trees. We assessed support for individual nodes using a bootstrap procedure of 10,000 replicates. Scale bar indicates amino acid substitutions per site.

Medicine Research Unit, Bangkok); Achara Laongnualpanich (Chiang Rai Prachanukroh Hospital, Chiang Rai, Thailand); Prapit Teparrakkul and Pramot Srisamang (Sappasithiprasong Hospital, Ubon Ratchathani, Thailand); Claire Ling (Shoklo Malaria Research Unit, Mae Sot, Thailand); Phan Huu Phuc and Le Thanh Hai (National Hospital of Pediatrics, Hanoi, Vietnam); Nguyen Van Kinh (National Hospital of Tropical Diseases, Hanoi); Bui Duc Phu (Hue Central Hospital, Hue, Vietnam); Nguyen Thanh Hung and Tang Chi Thuong (Children's Hospital 1, Ho Chi Minh City, Vietnam); Ha Manh Tuan (Children's Hospital 2, Ho Chi Minh City); Lam Minh Yen and Nguyen Van Vinh Chau (Hospital for Tropical Diseases, Ho Chi Minh City); Guy Thwaites, Heiman Wertheim, Le Van Tan, Motiur Rahman, and H. Rogier van Doorn (Oxford University Clinical Research Unit, Ho Chi Minh City); and Chuen-Yen Lau (National Institute of Allergy and Infectious Diseases, National Institutes of Health, Bethesda, Maryland, USA).

\section{Acknowledgments}

We thank Le Kim Thanh for her logistic support. We thank the patients for their participation in this study.

This study was funded by National Institute of Allergy and Infectious Diseases, US National Institutes of Health, and the Wellcome Trust of Great Britain (106680/B/14/Z and 204904/Z/16/Z). X.D. and E.D. were supported by the Blood Systems Research Institute and National Heart, Lung, and Blood Institute (grant no. R01 HL105770).

\section{About the Author}

Ms. Nguyen is a PhD student in life science at Open University, Milton Keynes, United Kingdom. Her research interests are virus discovery and evolution of emerging pathogens such as enteroviruses. 


\section{References}

1. Berg MG, Lee D, Coller K, Frankel M, Aronsohn A, Cheng K, et al. Discovery of a novel human pegivirus in blood associated with hepatitis C virus co-infection. PLoS Pathog. 2015; 11:e1005325. http://dx.doi.org/10.1371/journal.ppat.1005325

2. Kapoor A, Kumar A, Simmonds P, Bhuva N, Singh Chauhan L, Lee B, et al. Virome analysis of transfusion recipients reveals a novel human virus that shares genomic features with hepaciviruses and pegiviruses. MBio. 2015;6:e01466-15. http://dx.doi.org/10.1128/mBio.01466-15

3. Wang H, Wan Z, Xu R, Guan Y, Zhu N, Li J, et al. A novel human pegivirus, $\mathrm{HPgV}-2$ (HHpgV-1), is tightly associated with hepatitis $\mathrm{C}$ virus $(\mathrm{HCV})$ infection and $\mathrm{HCV} /$ human immunodeficiency virus type 1 coinfection. Clin Infect Dis. 2018;66:29-35. http://dx.doi.org/10.1093/cid/cix748

4. Wang H, Wan Z, Sun Q, Zhu N, Li T, Ren X, et al. Second human pegivirus in hepatitis $\mathrm{C}$ virus-infected and hepatitis $\mathrm{C}$ virus/ HIV-1 co-infected persons who injected drugs, China. Emerg Infect Dis. 2018;24:908-11.

5. Kandathil AJ, Breitwieser FP, Sachithanandham J, Robinson M, Mehta SH, Timp W, et al. Presence of human hepegivirus-1 in a cohort of people who inject drugs. Ann Intern Med. 2017;167:1-7. http://dx.doi.org/10.7326/M17-0085

6. Southeast Asia Infectious Disease Clinical Research Network. Causes and outcomes of sepsis in southeast Asia: a multinational multicentre cross-sectional study. Lancet Glob Health. 2017; 5:e157-67. http://dx.doi.org/10.1016/S2214-109X(17)30007-4

7. Nguyen AT, Tran TT, Hoang VMT, Nghiem NM, Le NNT, Le TTM, et al. Development and evaluation of a non-ribosomal random PCR and next-generation sequencing based assay for detection and sequencing of hand, foot, and mouth disease pathogens. Virol J. 2016;13:125. http://dx.doi.org/10.1186/ s12985-016-0580-9

8. Frankel M, Forberg K, Coller KE, Berg MG, Hackett J Jr, Cloherty G, et al. Development of a high-throughput multiplexed real time RT-PCR assay for detection of human pegivirus 1 and 2 . J Virol Methods. 2017;241:34-40. http://dx.doi.org/10.1016/ j.jviromet.2016.12.013

9. Ladner JT, Beitzel B, Chain PS, Davenport MG, Donaldson EF, Frieman M, et al.; Threat Characterization Consortium. Standards for sequencing viral genomes in the era of highthroughput sequencing.. VIROME: a standard operating procedure for analysis of viral metagenome sequences. MBio. 2014;5:e01360-14.

10. Bijvand Y, Aghasadeghi MR, Sakhaee F, Pakzad P, Vaziri F, Saraji AA, et al. First detection of human hepegivirus-1 (HHpgV-1) in Iranian patients with hemophilia. Sci Rep. 2018;8:5036. http://dx.doi.org/10.1038/s41598-018-23490-4

11. Barclay ST, Cooke GS, Holtham E, Gauthier A, Schwarzbard J, Atanasov $\mathrm{P}$, et al. A new paradigm evaluating cost per cure of HCV infection in the UK. Hepatol Med Policy. 2016;1:2. https://doi.org/10.1186/s41124-016-0002-z

12. Ireland G, Delpech V, Kirwan P, Croxford S, Lattimore S, Sabin C, et al. Prevalence of diagnosed HIV infection among persons with hepatitis C virus infection: England, 2008-2014. HIV Med. 2018 Jul 26 [Epub ahead of print].

Address for correspondence: To Anh Nguyen or Le Van Tan, Oxford University Clinical Research Unit, Ho Chi Minh City, Vietnam; email: anhnt@oucru.org ortanlv@oucru.org
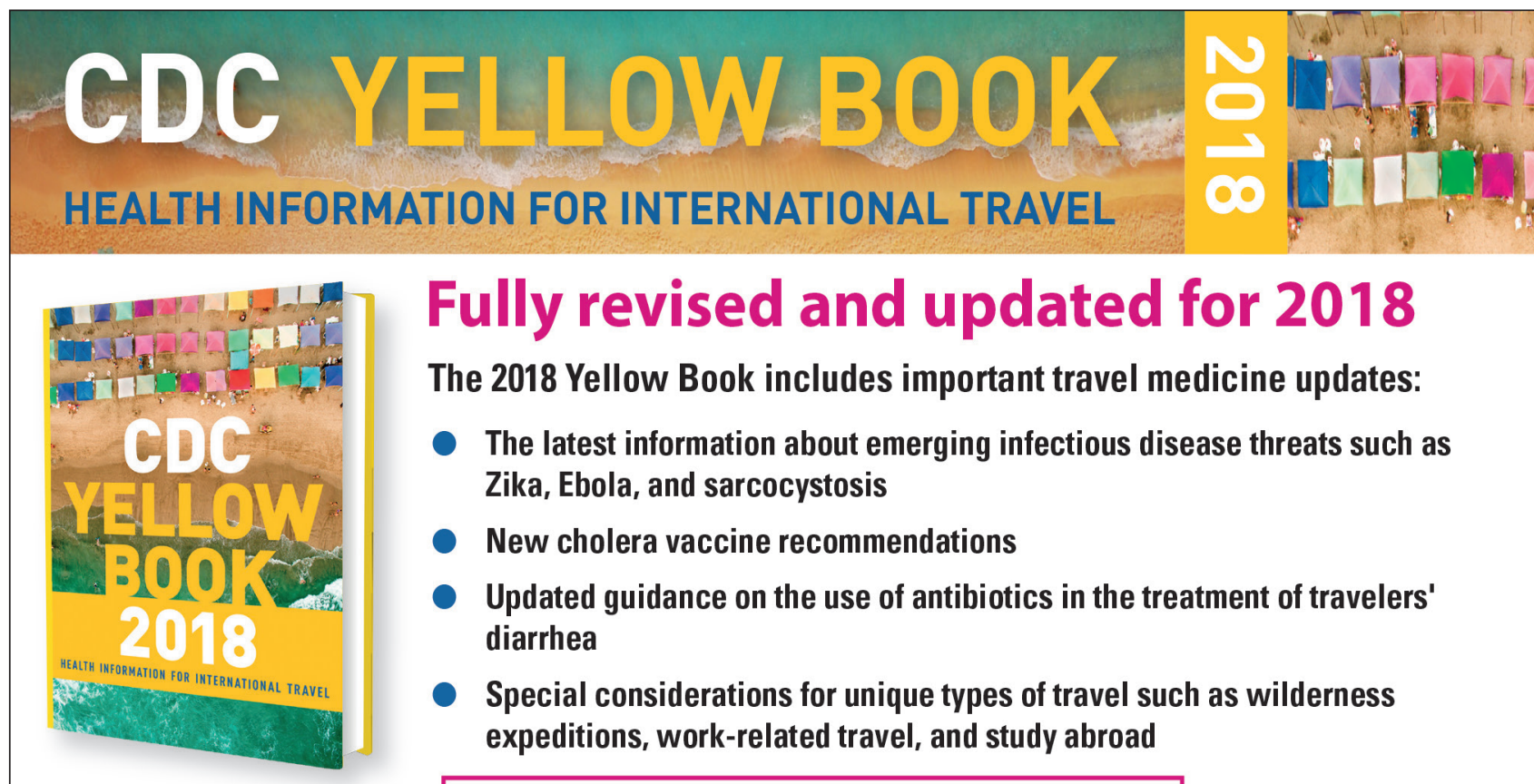

\section{Fully revised and updated for 2018}

\section{The 2018 Yellow Book includes important travel medicine updates:} The latest information about emerging infectious disease threats such as
Zika, Ebola, and sarcocystosis

- New cholera vaccine recommendations

- Updated guidance on the use of antibiotics in the treatment of travelers' diarrhea

\section{Special considerations for unique types of travel such as wilderness expeditions, work-related travel, and study abroad}

ISBN: 9780190628611 | \$49.95 | May 2017 | Paperback | 704 pages 